\title{
Comparison of Passive and Semi-Active Horizontal Platform Suspensions
}

\author{
Stefan SEGLA, Milos MUSIL
}

\begin{abstract}
In this paper modelling, control and optimization of a kinematically excited horizontal platform is presented. The platform with two independent mutually perpendicular suspension units is designed to mitigate horizontal vibration of the operator seat in the excavator cabin. Three types of suspension between the lower part of the platform and the cabin and between the lower part and the upper part of the platform are investigated, namely passive suspension, idealized semi-active suspension and suspension equipped with magnetorheological dampers. Their design parameters are optimized. The improvement of the magnetorheological/idealized semi-active platform suspension in reducing the vibration total value of the frequency weighted effective accelerations in two mutually perpendicular horizontal directions, compared with the passive platform suspension, is $26,3 \% / 70,8 \%$. The magnitude of the vibration total value of the passive/magnetorheological/idealized semi-active platform suspension is $0,4547 \mathrm{~m} \cdot \mathrm{s}^{-2}$ (a little uncomfortable) $/ 0,3352 \mathrm{~m} \cdot \mathrm{s}^{-2}$ (a little uncomfortable) $/ 0,1328 \mathrm{~m} \cdot \mathrm{s}^{-2}$ (not uncomfortable).
\end{abstract}

Keywords: horizontal platform; magnetorheological damper; optimization; passive suspension; semi-active suspension

\section{INTRODUCTION}

Operators of various land vehicles, machines and bucket-wheel excavators are exposed to vibrations due to their operation. Prolonged exposure to excessive vibrations has a significant effect on the operator's fatigue and can even lead to a deteriorating health state.

The biomechanical behaviour of the human body influences the perception of whole-body vibrations through the body inner organs resonances. These resonances lie in the range $1 \div 100 \mathrm{~Hz}$. As for the operators of land vehicles and excavators the most effected organ among the human body inner organs is spine (backbone or spinal/vertebral column) especially its parts called vertebra. For higher frequencies is the human body less and less sensitive. Movements with frequencies below $1 \mathrm{~Hz}$ produce a kind of motion sickness. In accordance with this knowledge the oscillatory comfort of the operator is in the paper assessed according to the procedure as prescribed by the 1997 ISO 2631-1 standard for comfort in public means of transport [1].

Medical research studies presented e.g. by Griffin in [2,3] showed the necessity of proper suspension design which would guarantee desired comfort of the operator. Another need is related to the controllability of land vehicles, excavators and various other machines.

A lot of research has been devoted to the reduction of vertical vibrations and relative displacements in various kinds of vehicles and vehicle seats. A conventional seat suspension involves passive springs and dampers. Multicriteria optimization techniques are often applied to determine optimum values of suspension damping and spring stiffness parameters which leads to optimum dynamic performance of passive suspensions. Stein et al. [4] studied locomotive driver's seat vertical suspension with an adjustable damper. A seat model was augmented with a seat cushion dynamic model and two-parameter optimization was performed. Maciejewski et al. [5] presented a comparison of transmissibility functions of conventional and modified passive suspension of vehicle seats. Vibro isolation properties of the modified system were improved through modification of an air-spring and a shock absorber. Segla and Trisovic [6] used 1,5-degree of freedom (DOF) Zener's model to model and optimize a vehicle seat suspension. Furthermore, the paper presents possible ways in which dynamic characteristics of the seat can be improved if a passive dynamic vibration absorber is used. In [7] possibilities of multi-objective optimization for the improvement of dynamic characteristics of seat suspension systems and quarter-car models were presented.

Active suspension involves replacement suspension elements with an actuator. It uses external power supply which generates active force that is regulated by a control system reacting to the system variables (usually displacement, velocity and acceleration). This system is still costly as it involves a number of precision components, and its energetic demand is high. The most important characteristics of these systems can be found e.g. in [8, 9]. Misselhorn et al. [10] presented a test method. During simulation real-time measurements on physical hardware replace a mathematical model of the vehicle model. Maciejewski et al. in [11] investigated dynamic response of an active vibroisolating pneumatic suspension seat. Active control of the air-spring force used a triple feedback loop control system. Belgacem et al. [12] presented active vibration control on a quarter-car for cancelation of road noise disturbance.

Semi-active suspensions fill the gap between active and passive systems. The idea of the active system can be modified so that the actuator is only capable of energy dissipation. The semi-active suspension system is characterized by a rapidly adjustable damper parallel with a spring which supports the static load. Hardware requirements are considerably lower. Required external energy is in general very small [8]. Magnetorheological (MR) dampers are mostly used semi-active devices in automotive engineering. The key feature of an MR damper is the magnetorheological oil with rheological properties which can be altered by a magnetic field. By controlling the field variable damping force can be produced. Overview of semi-active control algorithms (balance, skyhook and ground-hook algorithms), MR and friction dampers, vehicle modelling and human body analysis can be found in [8]. Georgiou et al. [6] presented a comparison of passive and semi-active suspension systems with a constant horizontal speed over roads involving an isolated or a distributed geometric irregularity. Optimization was 
based on three performance criteria related to ride comfort, suspension travel and road holding. Ballo [13] compared the properties of an active and semi-active suspension. Segla et al. in [14] investigated vibroisolation properties of a passive, semi-active and MR horizontal platform suspension with three degrees of freedom.

In this paper a new variant of the horizontal platform with two independent suspensions in two perpendicular directions is investigated and the results are compared with the results of the platform with three degrees of freedom presented in [14].

First, mathematical models of the lower and upper part of the horizontal platform with passive, idealized semiactive and MR suspensions are built. To control the idealized semi-active and MR suspensions a well-known conventional skyhook control law is applied. Finally, selected parameters of both mechanical and control parts of the suspension systems are optimized and their dynamic properties are compared.

\section{DYNAMIC AND MATHEMATICAL MODELS}

The horizontal platform consists of two mutually perpendicular units each with its own independent suspension, Fig. 1. Both units are kinematically excited through the operator cabin vibration.

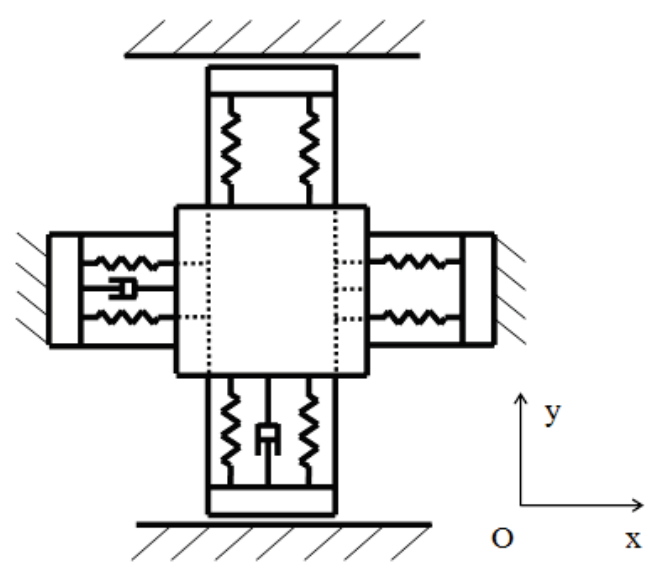

Figure 1 Horizontal platform with two mutually perpendicular units

Kinematic excitation was experimentally obtained from field measurements under real operating conditions of average vibration intensity in the cabin of a bucketwheel excavator SchRs 1320 [15] in a coal strip mine in Bílina (Czech Republic), Fig. 2. The bucket-wheel excavator is one of the most suitable applications of the horizontal platform.

A Brüel \& Kjær Type 415-B accelerometer specially designed for the field measurement of whole-body vibration in passenger and work vehicles was used. The accelerometer was mounted on the cabin deck under the operator's seat and detected vibration acceleration in vertical, back-to-front, and side-to-side direction. The highest measured frequency of $100 \mathrm{~Hz}$ covers the frequency range $1 \div 80 \mathrm{~Hz}$ as prescribed by the 1997 ISO 2631-1 standard. The signals were acquired at 400 samples per second for $162 \mathrm{~s}$. The accelerometer was connected to the DEWE-5000 measuring system with A/D measuring cards. Displacements were obtained by double integration of acceleration with frequency filtration without frequency components $0 \div 1 \mathrm{~Hz}$ with Matlab.

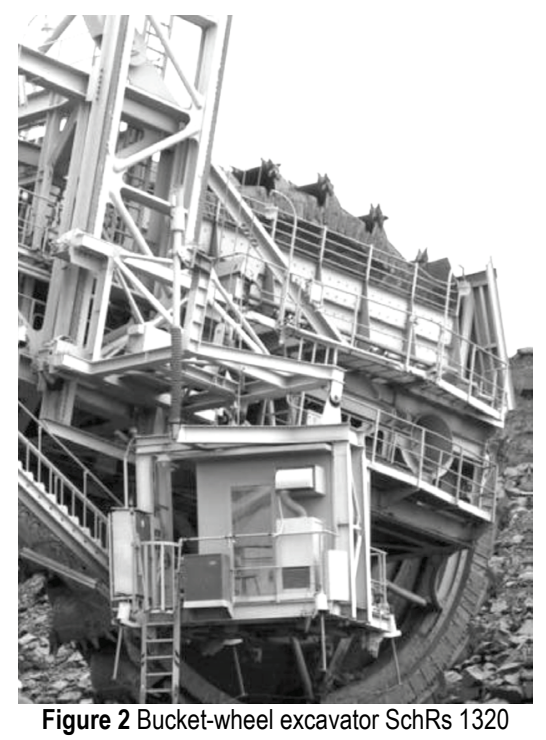

\subsection{Passive Suspension of the Platform}

The horizontal platform, with the operator seat installed on it, has two independent suspensions in two mutually perpendicular directions $(x, y)$ realized by two linear bearings for translational motion. The lower part of the platform enables motion in the x-direction and the upper one in the y-direction, Fig. 1.

The platform is kinematically excited in the $x$-direction by the excitation function $u(t)$ and in the $y$-direction by the excitation function $v(t)$, Fig. 3 and Fig. 4.
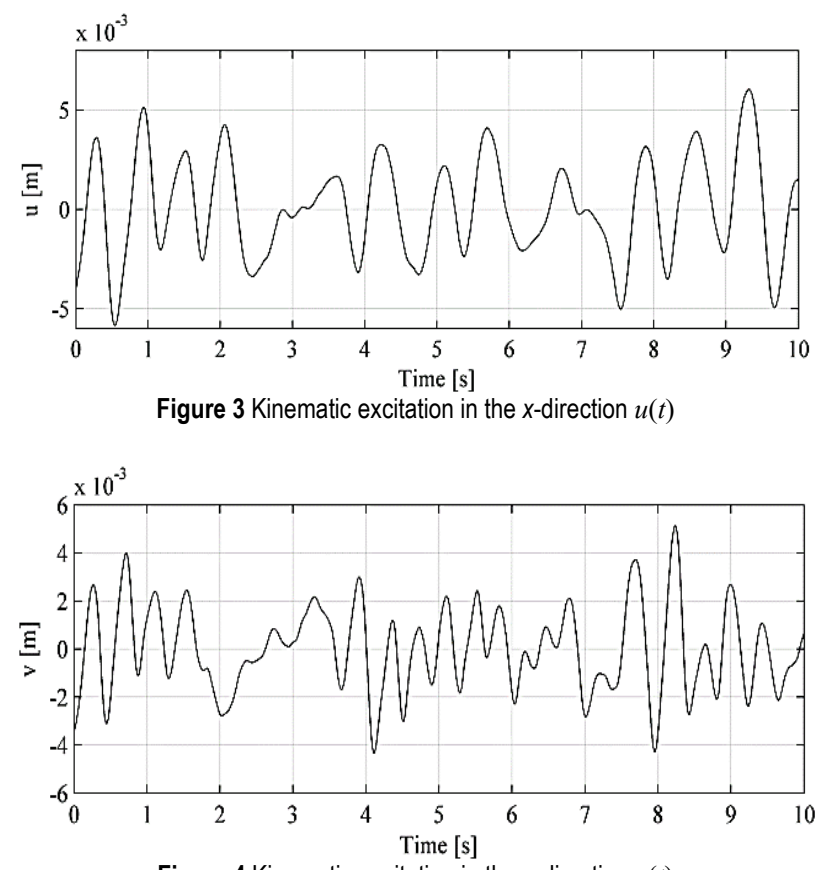

Figure 4 Kinematic excitation in the $y$-direction $v(t)$

The spectral analysis of the vibration acceleration showed that the frequency of the digging forces (about $2,418 \mathrm{~Hz}$ ) lies in the frequency interval, which has an important influence on the human body inner organs.

Dynamic model of the lower part is shown in Fig. 5. Its mathematical model has the form 
$m_{x} \ddot{x}+c_{x}(\dot{x}-\dot{u})+4 k_{x}(x-u)=0$,

where $m_{x}$ is the mass of the lower part of the platform, $c_{x}$ is the damping coefficient and $k_{x}$ is the spring stiffness. As design variables for optimization the following two parameters are selected: $c_{x}$ and $k_{x}$. The objective function and optimization results are described in section 3.

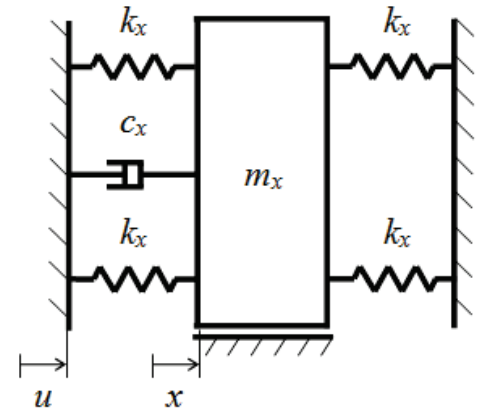

Figure 5 Dynamic model of the lower part of the platform

The same procedure was applied for optimization of the upper part of the platform. Its dynamic model is presented in Fig. 6 and its mathematical model is as follows

$m_{y} \ddot{y}+c_{y}(\dot{y}-\dot{v})+4 k_{y}(y-v)=0$,

where $m_{y}$ is the mass of the upper part of the platform, $c_{y}$ is the damping coefficient and $k_{y}$ is the spring stiffness.

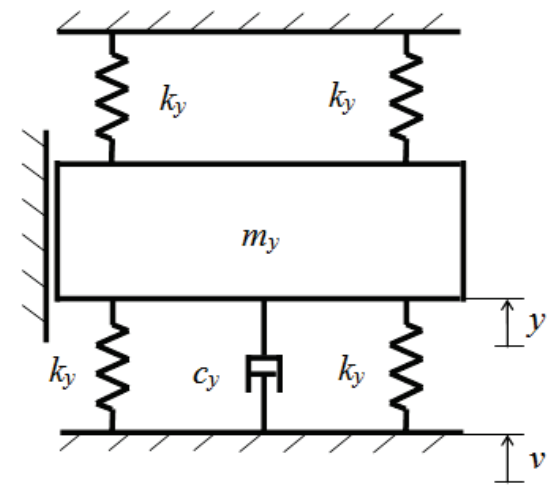

Figure 6 Dynamic model of the upper part of the platform

Parameters $c_{y}$ and $k_{y}$ are selected as design variables for optimization.

\subsection{Idealized Semi-Active Suspension of the Platform}

The idealized semi-active suspension enables us to judge force intervals of real MR dampers and to determine how efficient they are in comparison with the idealized semi-active dampers. The drawbacks of real MR dampers (time delays and nonzero damping forces in the off states) can significantly deteriorate their efficiency.

Dynamic model of the idealized semi-active suspension of the lower part of the platform is shown in Fig. 7.

The idealized semi-active suspension uses idealized semi-active dampers instead of passive dampers and, hence, differs from the passive suspension depicted in Fig. 5. The control algorithm of the semi-active damper is based on the conventional skyhook control. The task of the damper is to generate the same force with the same direction and magnitude as the fictitious skyhook damper with damping coefficient $c_{s k y, x}$ would generate while acting on the platform. The fictitious skyhook damper is placed between points 1 and 1', Fig. 7. The point 1 ' absolute position is fixed. The semi-active damper can generate damping force in a desired direction only if absolute velocity $\dot{x}$ of point 1 and relative velocity between the platform and the excavator cabin $\dot{x}$ are of the same direction. This condition can be expressed by the following inequality

$\dot{x}(\dot{x}-\dot{u})>0$

Mathematical model of the system in Fig. 7 is

$m_{x} \ddot{x}+F_{s a, x}+4 k_{x}(x-u)=0$,

where the semi-active damping force generated by the idealized skyhook damper is

$F_{s a, x}=\left\{\begin{array}{ccc}c_{s k y, x} \dot{x} & \text { if } & \dot{x}(\dot{x}-\dot{u})>0, \\ 0 & \text { if } & \dot{x}(\dot{x}-\dot{u}) \leq 0,\end{array}\right.$

where $c_{s k y, x}$ is the damping coefficient of the fictitious skyhook damper.

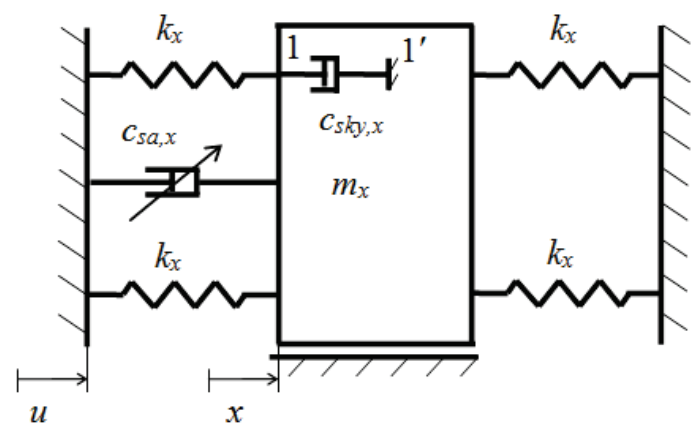

Figure 7 Dynamic model of the idealized semi-active suspension of the lower part of the platform

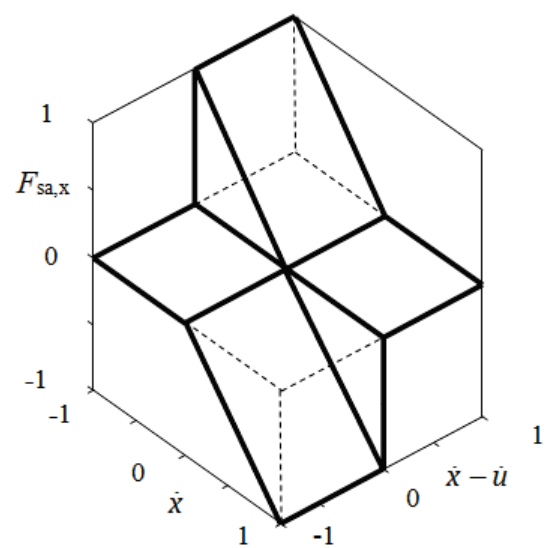

Figure 8 3D plot of the damping force $c_{s k y, x}$ for conventional skyhook control

Graphical interpretation of the conventional skyhook law expressed by Eq. (5) is shown in Fig. 8. 
Skyhook damping coefficient $c_{s k y, x}$ and spring stiffness coefficient $k_{x}$ are selected as design variables.

The same procedure was applied for optimization of the upper part of the platform. Its dynamic model is presented in Fig. 9 and mathematical model is

$m_{y} \ddot{y}+F_{s a, y}+4 k_{y}(y-v)=0$,

where the semi-active damping force generated by the idealized skyhook damper is

$F_{s a, y}=\left\{\begin{array}{ccc}c_{s k y, y} \dot{y} & \text { if } & \dot{y}(\dot{y}-\dot{v})>0, \\ 0 & \text { if } & \dot{y}(\dot{y}-\dot{v}) \leq 0,\end{array}\right.$

where $c_{s k y, y}$ is the damping coefficient of the fictitious skyhook damper (analogy of $c_{s k y, x}$ ), Fig. 9.

In this case the skyhook damping coefficient $c_{s k y, y}$ and spring stiffness coefficient $k_{y}$ are selected as design variables.

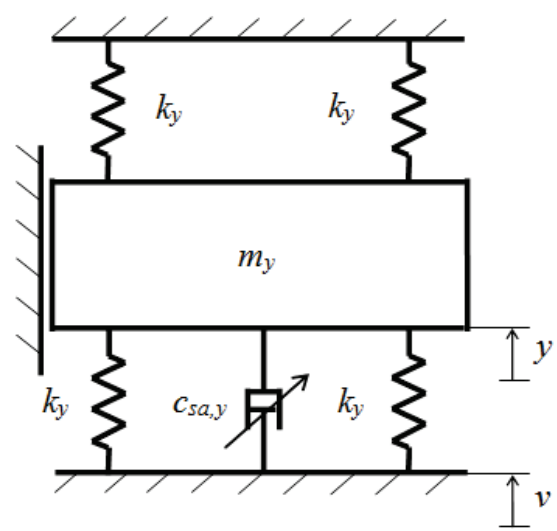

Figure 9 Dynamic model of the idealized semi-active suspension of the upper part of the platform

\subsection{Magnetorheological Suspension of the Platform}

In this case MR dampers are used (Fig. 10) with discrete skyhook control of damping forces instead of passive dampers.

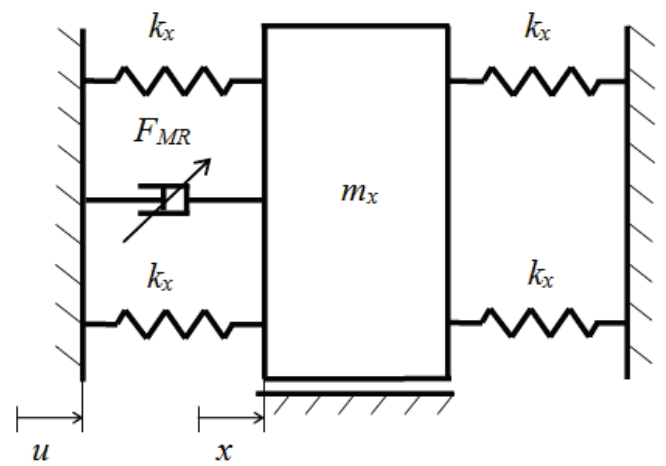

Figure 10 Dynamic model of MR suspension of the lower part of the platform is

Mathematical model of the lower part of the platform

$m_{x} \ddot{x}+F_{M R}+4 k_{x}(x-u)=0$, where the MR force $F_{M R}$ is described by a modified BoucWen model [16] based on experimental data

$$
\begin{aligned}
F_{M R}=c_{1} \dot{y}+k_{1}\left(x-u-x_{0}\right), \\
\dot{y}=\frac{1}{c_{0}+c_{1}}\left[\alpha z+c_{0}(\dot{x}-\dot{u})+k_{0}(x-u-y)\right], \\
\dot{z}=-\gamma|\dot{x}-\dot{u}-\dot{y}| z|z|^{n-1}-\beta(\dot{x}-\dot{u}-\dot{y})|z|^{n}+ \\
\quad+A(\dot{x}-\dot{u}-\dot{y}),
\end{aligned}
$$

where $c_{1}$ represents viscous damping at low velocities, $c_{0}$ represents viscous damping at high velocities, $k_{0}$ represents spring stiffness at high velocities, $k_{1}$ is accumulator stiffness, $x-u$ is piston relative displacement, $x_{0}$ is initial deflection of the accumulator gas spring, $y$ is internal displacement of the damper and $z$ is the evolutionary variable. $\alpha$ is the scaling value for the Bouc-Wen model, $\gamma$, $\beta, A$ and $n$ are constant parameters used to adjust scale and shape of the hysteresis loop, respectively.

Parameters $c_{0}, c_{1}$ and $\alpha$ are assumed to be a function of applied current $I$

$$
\begin{aligned}
& \alpha=\alpha_{0}+\alpha_{b} I, \\
& c_{0}=c_{0 a}+c_{0 b} I, \\
& c_{1}=c_{1 a}+c_{1 b} I .
\end{aligned}
$$

Constant parameters of the MR damper $\left(c_{0 a}, c_{0 b}, c_{1 a}\right.$, $\left.c_{1 b}, \alpha_{a}, \alpha_{b}, k_{0}, k_{1}, x_{0}, \beta, A, \gamma, n\right)$ used in the suspension of the lower part are given in [16]. It is of great importance to choose MR dampers with parameters which are suitable in relation to force range, its magnitude in the off state and time delay.

According to discrete skyhook control the applied current $I$ is

$I= \begin{cases}I & \text { if } \dot{x}(\dot{x}-\dot{u})>0 \\ 0 & \text { otherwise }\end{cases}$

The applied current $I$ and spring stiffness coefficient $k_{x}$ are selected as design variables for optimization.

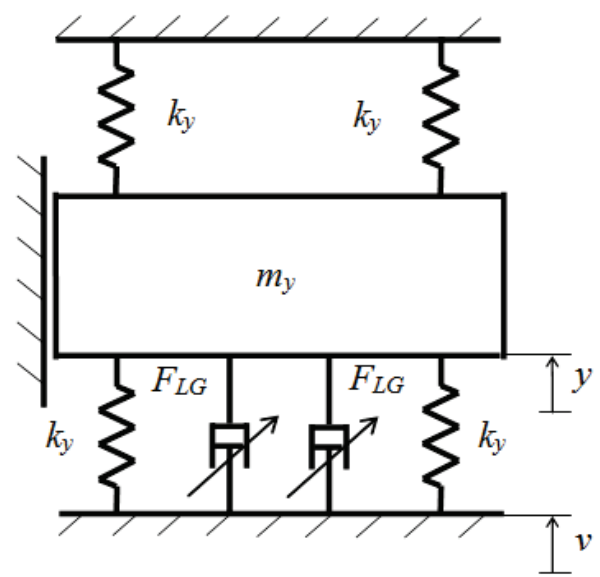

Figure 11 Dynamic model of MR suspension of the upper part of the platform

The MR dampers used in the lower part of the platform suspension are not appropriate for suspension of the upper 
part. Numerical simulation showed that they do not give good results for masses lower than $200 \mathrm{~kg}$. This is the reason why two different small-scale MR dampers (generating maximum damping force of $80 \mathrm{~N}$ ) are used in suspension of the platform upper part, Fig. 11. They are based on the LuGre friction model proposed in [17]. This model captures Stribeck effect, hysteresis, spring-like characteristics and varying break-away force.

Mathematical model of the platform is

$m_{y} \ddot{y}+2 F_{L G}+4 k_{y}(y-v)=0$,

where $F_{L G}$ is the LuGre friction force

$F_{L G}=\sigma_{0} z+\sigma_{1} \dot{z}+\sigma_{2}(\dot{y}-\dot{v})$,

where $z$ is an internal variable (an average deflection of the bristles, or MR fluid particle chains), $\dot{y}-\dot{v}$ is relative velocity between the interacting surfaces, $\sigma_{0}$ is stiffness of bristles, $\sigma_{1}$ is bristle damping and $\sigma_{2}$ is viscous damping coefficient.

Internal variable $z$ is given by

$\dot{z}=(\dot{y}-\dot{v})-\frac{\sigma_{0}(\dot{y}-\dot{v})}{g(\dot{y}-\dot{v})} z$,

where a positive function $g(\dot{y}-\dot{v})$ depending on material properties describes the Stribeck effect and has the form

$g(\dot{y}-\dot{v})=F_{C}+\left(F_{S}-F_{C}\right) \mathrm{e}^{-\left(\frac{\dot{y}-\dot{v}}{v_{S}}\right)^{2}}$,

where $F_{C}$ is the Coulomb friction force, $F_{S}$ is the stiction force and $v_{S}$ denotes the Stribeck velocity.

The Coulomb friction force $F_{C}$ is approximated for the RD 1097-01 MR damper by the modified Langevin function [17]

$$
F_{C}(I)=\left\{\begin{array}{l}
F_{0}+A_{C}\left[\operatorname{coth}\left(\frac{I}{B_{C}}\right)-\frac{B_{C}}{I}\right]^{2} \text { for } I \neq 0, \\
F_{0} \text { for } I=0,
\end{array}\right.
$$

where $I$ is the input current, $F_{0}$ is a residual Coulomb friction force at $I=0, A_{C}$ and $B_{C}$ are constants.

The following MR damper parameters are expressed as functions of the input current $I$

$$
\begin{aligned}
& \sigma_{0}(I)=\sigma_{0 A} I+\sigma_{0 b}, \\
& \sigma_{1}(I)=\sigma_{1 A} I+\sigma_{1 b}, \\
& \sigma_{2}(I)=\sigma_{2 A} I+\sigma_{2 b}, \\
& F_{S}(I)=F_{S A} I+F_{S B}, \\
& v_{S}(I)=v_{S A} I+v_{s B},
\end{aligned}
$$

Constant parameters $\left(F_{0}, A_{C}, B_{C}, \sigma_{0 A}, \sigma_{0 B}, \sigma_{1 A}, \sigma_{1 B}, \sigma_{2 A}, \sigma_{2 B}\right.$, $\left.F_{S A}, F_{S B}, v_{S A}, v_{S B}\right)$ of approximating functions (21) to (25) are given in [17].

The input current for the discrete skyhook control algorithm is expressed in the form

$I= \begin{cases}I & \text { if } \dot{y}(\dot{y}-\dot{v})>0, \\ 0 & \text { otherwise }\end{cases}$

The applied current $I$ and spring stiffness coefficient $k_{y}$ are selected as design variables for optimization in the next section.

\section{FORMULATION OF THE OPTIMIZATION PROBLEM}

Optimization of platform suspension parameters is necessary because of two conflicting requirements - minimization of platform accelerations to protect operator's health (maximization of his comfort),

- minimization of platform relative displacements to improve controllability of the bucket-wheel excavator or any other land machine.

The best compromise between the opposite criteria mentioned above create a nonlinear optimization problem. An appropriate solution procedure is based on minimization of the objective function

$f_{o p}=w \frac{f_{a c c}}{f_{a c c, n o m}}+(w-1) \frac{f_{\text {disp }}}{f_{\text {disp }, \text { nom }}}$

where $w$ is the weighting coefficient which depends on the significance of the criteria $(w \in\langle 0,1\rangle)$. The function $f_{\text {acc }}$ expresses the platform frequency-weighted effective acceleration (the root mean square of the weighted acceleration) in the $x$ - and $y$-directions according to the 1997 ISO 2631-1 standard

$$
f_{a c c}=\sqrt{\frac{1}{T} \int_{0}^{T} \ddot{x}_{w}^{2}(t) \mathrm{d} t}\left(\text { or } \sqrt{\frac{1}{T} \int_{0}^{T} \ddot{y}_{w}^{2}(t) \mathrm{d} t}\right)
$$

where $\ddot{x}_{w}$ and $\ddot{y}_{w}$ are frequency weighted accelerations and function $f_{\text {disp }}$ expresses the platform effective relative displacement (the root mean square of the relative displacement) in the $x$ - and $y$-directions

$$
\begin{gathered}
f_{d i s p}=\sqrt{\frac{1}{T} \int_{0}^{T}(x(t)-u(t))^{2} \mathrm{~d} t} \\
\left(\text { or } \sqrt{\frac{1}{T} \int_{0}^{T}(y(t)-v(t))^{2} \mathrm{~d} t}\right),
\end{gathered}
$$

where $T$ is time of integration which must be long enough to capture the dynamics of suspension systems.

Both effective values $f_{a c c}$ and $f_{\text {disp }}$ in Eqs. (28) and (29) are divided by their nominal values (defined for mean values of design variables in their search intervals), 
because the values of these quantities are not commensurable.

\subsection{Optimization Results for the Platform Suspensions}

Specified values of the platform are: mass of the lower part of the platform (including the mass of the upper part) $m_{x}=220 \mathrm{~kg}$, mass of the upper part of the platform $m_{y}=$ $170 \mathrm{~kg}$. The weighting coefficient is $w=0,9$ (operator's comfort is preferred) and time of integration is $T=20 \mathrm{~s}$.

By means of Global Optimization Toolbox User's Guide [18] the following results of optimization were obtained

- passive suspension: lower part: $k_{x, \text { opt }}=4119,7 \mathrm{~N} / \mathrm{m}$, $c_{x, \text { opt }}=1108,8 \mathrm{~N} . \mathrm{s} / \mathrm{m}$, upper part: $k_{y, \text { opt }}=3691,4 \mathrm{~N} / \mathrm{m}$, $c_{y, \text { opt }}=1169,1 \mathrm{~N} . \mathrm{s} / \mathrm{m}$,

- idealized semi-active suspension: lower part: $k_{x, o p t}=$ $3520,6 \mathrm{~N} / \mathrm{m}, c_{s k y x, \text { opt }}=6904,5 \mathrm{~N} . \mathrm{s} / \mathrm{m}$, upper part: $k_{y, o p t}=$ $3260,3 \mathrm{~N} / \mathrm{m}, c_{\text {skyy,opt }}=5409,8 \mathrm{~N} . \mathrm{s} / \mathrm{m}$,

- $\quad$ MR suspension: lower part: $k_{x, \text { opt }}=3005,4 \mathrm{~N} / \mathrm{m}, I_{\text {opt }}=$ 1,08 A, upper part: $k_{y, o p t}=3010,7 \mathrm{~N} / \mathrm{m}, I_{\text {opt }}=3,02 \mathrm{~A}$.

Tab. 1 presents effective relative displacements as well as frequency-weighted effective accelerations. From the last column of Tab. 1 it is obvious that both idealized semiactive and magnetorheological suspensions bring significant improvements if compared with passive suspension.

Table 1 Effective relative displacements and frequency-weighted effective accelerations

\begin{tabular}{|c|c|c|c|}
\hline $\begin{array}{c}\text { Suspension and } \\
\text { direction }\end{array}$ & $\begin{array}{c}\text { Effective } \\
\text { relative } \\
\text { displacement } \\
(\mathrm{m})\end{array}$ & $\begin{array}{c}\text { Frequency } \\
\text { weighted } \\
\text { effective } \\
\text { acceleration } \\
\left(\mathrm{m} \cdot \mathrm{s}^{-2}\right)\end{array}$ & $\begin{array}{c}\text { Improvement of } \\
\text { acceleration (\%) }\end{array}$ \\
\hline Passive $x$ & 0,00260 & 0,3063 & - \\
\hline Passive $y$ & 0,00240 & 0,3361 & - \\
\hline $\begin{array}{c}\text { Idealized semi- } \\
\text { active } x\end{array}$ & 0,00085 & 0,0872 & 71,5 \\
\hline $\begin{array}{c}\text { Idealized semi- } \\
\text { active } y\end{array}$ & 0,00097 & 0,1002 & 70,2 \\
\hline MR $x$ & 0,00220 & 0,2234 & 27,1 \\
\hline MR $y$ & 0,00190 & 0,2499 & 25,6 \\
\hline
\end{tabular}

After calculating the frequency weighted effective acceleration in $x$-direction $a_{w x}$ and y-direction $a_{w y}$, the frequency weighted effective acceleration total value $a_{V}$ is given by

$a_{V}=\left(a_{w x}^{2}+a_{w y}^{2}\right)^{1 / 2}$

Its value for passive/idealized semi-active/MR suspension is $0,4547 \mathrm{~m} \cdot \mathrm{s}^{-2} / 0,1328 \mathrm{~m} \cdot \mathrm{s}^{-2} / 0,3352 \mathrm{~m} \cdot \mathrm{s}^{-2}$. The improvement of the idealized semi-active/MR suspension compared with the passive suspension is $70,8 \% / 26,3 \%$.

Fig. 12 and Fig. 13 depict platform displacement and acceleration of MR suspension. The time interval of $20 \mathrm{~s}$ was reduced to $10 \mathrm{~s}$ for better visibility of details.

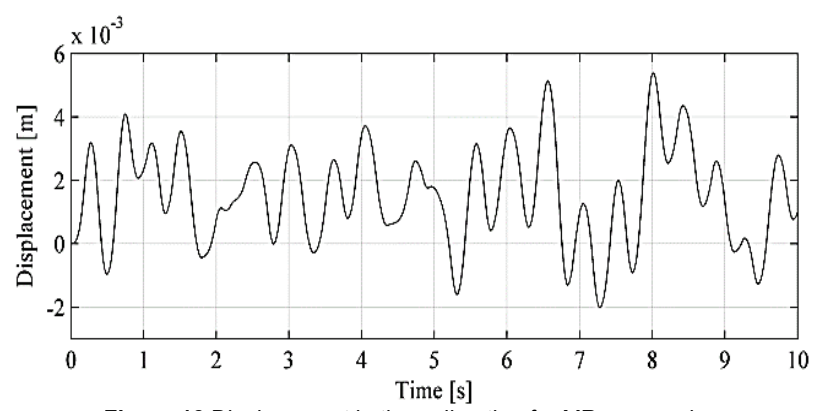

Figure 12 Displacement in the $x$-direction for MR suspension

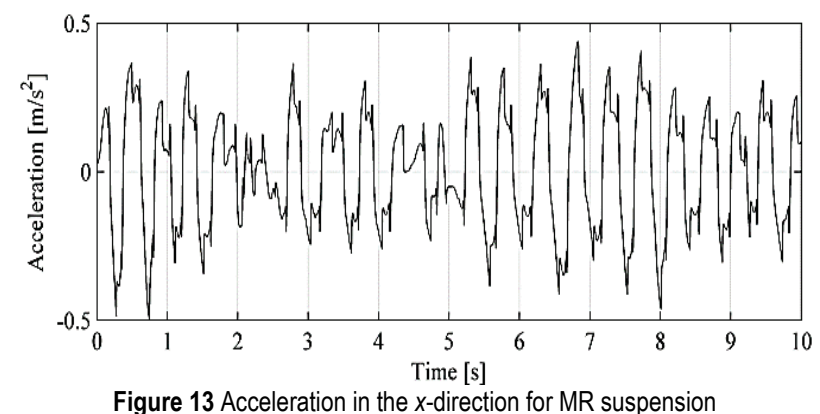

\section{PLATFORM VARIANT WITH THREE DOF}

This platform (presented in [14]) consists of a rectangular plate with three degrees of freedom (DOF), Fig. 14. Its simulation model created in the computer program ADAMS is presented in Fig. 15. Special ball bearings are assumed to be used between the excavator cabin and the platform and again three various types of suspensions between the platform and the excavator cabin were investigated.

Tab. 2 presents the effective relative displacements and frequency-weighted effective accelerations. The last column of the table shows that both semi-active suspensions bring significant improvements also for this variant if compared with the passive suspension.

Table 2 Effective relative displacements and frequency-weighted effective accelerations for the platform variant with three DOF

\begin{tabular}{|c|c|c|c|}
\hline $\begin{array}{c}\text { Suspension and } \\
\text { direction }\end{array}$ & $\begin{array}{c}\text { Effective } \\
\text { relative } \\
\text { displacement } \\
(\mathrm{m})\end{array}$ & $\begin{array}{c}\text { Frequency } \\
\text { weighted } \\
\text { effective } \\
\text { acceleration } \\
\left(\mathrm{m} \cdot \mathrm{s}^{-2}\right)\end{array}$ & $\begin{array}{c}\text { Improvement of } \\
\text { acceleration (\%) }\end{array}$ \\
\hline Passive $x$ & 0,00230 & 0,2533 & - \\
\hline Passive $y$ & 0,00220 & 0,2455 & - \\
\hline $\begin{array}{c}\text { Idealized semi- } \\
\text { active } x\end{array}$ & 0,00072 & 0,1855 & 26,8 \\
\hline $\begin{array}{c}\text { Idealized semi- } \\
\text { active } y\end{array}$ & 0,00083 & 0,1866 & 24,0 \\
\hline MR $x$ & 0,00150 & 0,2124 & 16,1 \\
\hline MR $y$ & 0,00140 & 0,2043 & 16,8 \\
\hline
\end{tabular}

The frequency weighted effective acceleration total value $a_{\mathrm{V}}$ for passive/idealized semi-active/MR suspension is $0,3527 \mathrm{~m} \cdot \mathrm{s}^{-2} / 0,2631 \mathrm{~m} \cdot \mathrm{s}^{-2} / 0,2947 \mathrm{~m} \cdot \mathrm{s}^{-2}$. The improvement of the idealized semi-active/MR suspension compared with the passive suspension is $25,4 \% / 16,4 \%$.

In Fig. 16 platform displacement in the $x$-direction is presented and in Fig. 17 platform accelerations of passive versus MR suspension in the $x$-direction are shown. The time interval of $20 \mathrm{~s}$ was reduced to $10 \mathrm{~s}$ for better visualization of details. 


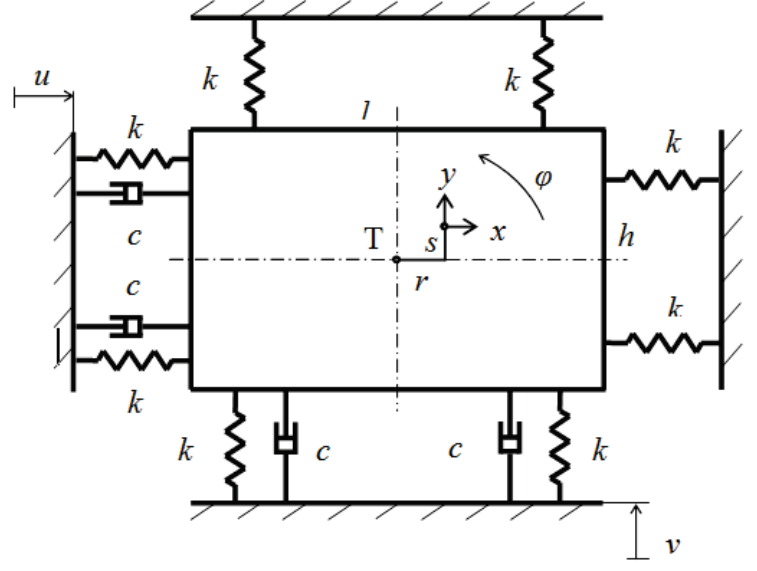

Figure 14 Platform variant with three DOF

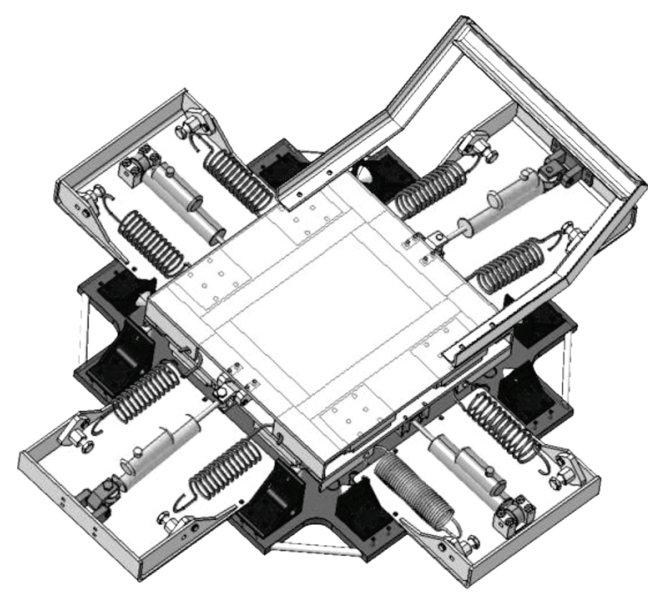

Figure 15 Simulation model of the platform variant with three DOF

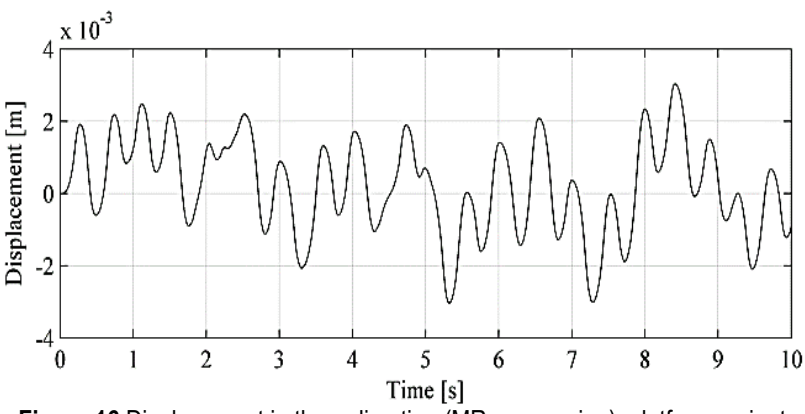

Figure 16 Displacement in the $x$-direction (MR suspension), platform variant with three DOF

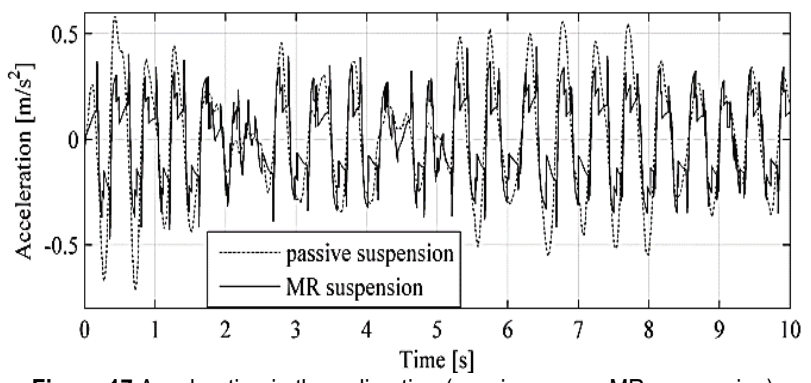

Figure 17 Acceleration in the $x$-direction (passive versus MR suspension), platform variant with three DOF

\section{CONCLUSION}

The paper investigates horizontal platform with two independent suspensions in two perpendicular directions, each with three different suspension systems (passive, idealized semi-active and magnetorheological) which can be used in the cabin of an excavator, other land machines and also vehicles. Their parameters were optimized in the time domain with objective functions expressing minimization of two conflicting requirements - frequencyweighted effective accelerations of the platform and effective relative displacements between the platform and machine cabin. The results of numerical optimization show significant reduction of platform vibrations not only in the case of idealized semi-active platform suspension but also in the case of the magnetorheological platform suspension as compared with the passive platform suspension.

The total value of the frequency weighted effective acceleration of the practically important magnetorheological platform suspension can be characterized according to the 1997 ISO 2631-1 standard for comfort in means of transport as a little uncomfortable.

In the future research the effects of vibration of both the horizontal platform and the operator's seat (vertical direction) on the comfort of the operator will be analyzed according to the criteria set out in [1], including the allowable vibration exposure time.

The proposed platform suspension system with just one DOF (one independent suspension) can also be utilized in automotive industry for the horizontal driver seat suspension in the direction of drive. However, in this case the reaction of the driver to the steering wheel (exerted by hands) needs to be taken into account. Such a system can provide a proper isolation of the driver in horizontal direction. The optimization algorithm proposed in the paper can be used to find an appropriate compromise between the desired reduction of vibrations transmitted to the driver (in both horizontal and vertical directions) and the conflicting requirement for minimization of the suspension travel. In this way both the improved driver comfort and the enhanced ability to drive a vehicle can be achieved.

\section{Acknowledgements}

The work presented in this article was supported by Scientific Grant Agency of Ministry of Education of the Slovak Republic and Slovak Academy of Sciences (Grant No. $1 / 0731 / 16$ ).

\section{REFERENCES}

[1] ISO 2631-1:1997. Mechanical vibration and shock Evolution of human exposure to whole-body vibration -Part 1: General requirements. International Organization for Standardization, Geneva.

[2] Griffin, M. (1994). Handbook of Human Vibrations. Academic Press, London.

[3] Griffin, M. (2007). Discomfort from feeling vehicle vibration. Vehicle System Dynamics, 45(7-8), 679-698. https://doi.org/10.1080/00423110701422426

[4] Stein, G. J., Múčka, P., \& Gunston, T. P. (2009). A study of locomotive driver's seat vertical suspension system with adjustable damper. Vehicle System Dynamics, 47(3), 363386. https://doi.org/10.1080/00423110802148920

[5] Maciejewski, I., Meyer, L., \& Krzyzynski, T. (2009). Modelling and multi-criteria optimisation of passive seat suspension vibro-isolating properties. Journal of Sound and Vibration, 324(1-2), 520-538. https://doi.org/10.1016/j.jsv.2009.02.021 
[6] Segla, S. \& Trišović, N. (2013). Modeling and optimization of passive seat suspension. American Journal of Mechanical Engineering, $\quad 1(7), \quad 407-411$. http://pubs.sciepub.com/ajme/1/7/51/index.html

[7] Georgiou, G., Verros, G., \& Natsiavas, S. (2007). Multiobjective optimization of quarter-car models with a passive or semi-active suspension system. Vehicle System Dynamics, 45(1), 77-92. https://doi.org/10.1080/00423110600812925

[8] Venhovens, P. J. Th. (1993). Optimal control of vehicle suspensions. Doctoral Thesis, Delft University of Technology, Faculty of Mechanical Engineering.

[9] Guglielmino, E., Sireteanu, T., Stammers, Ch. W., Ghita, G., \& Giuclea, M. (2008). Semi-active Suspension Control. Improved vehicle Ride and Road Friendliness. Springer, London.

[10] Misselhorn, W. E., Theron, N. J., \& Els, P. S. (2006). Investigation of hardware-in-the-loop for use in suspension development. Vehicle System Dynamics, 44(1), 65-81. https://doi.org/10.1080/00423110500303900

[11] Maciejewski, I., Meyer, L., \& Krzyzynski, T. (2010). The vibration damping effectiveness of an active seat suspension system and its robustness to varying mass loading. Journal of Sound and Vibration, 329(19), 3898-3914. https://doi.org/10.1016/j.jsv.2010.04.009

[12] Belgacem, W., Berry, A., \& Masson, P. (2012). Active vibration control on a quarter-car cancelation of road noise disturbance. Journal of Sound and Vibration, 331(14), 32403254. https://doi.org/10.1016/j.jsv.2012.02.030

[13] Ballo, I. (2007). Comparison of the properties of active and semiactive suspension. Vehicle System Dynamics, 45(11), 1065-1073. https://doi.org/10.1080/00423110701191575

[14] Segla, S., Zmindak, M., \& Orecny, M. (2015). Passive and semi-active vibroisolation of a horizontal platform. Proceedings of the $13^{\text {th }}$ International Conference Dynamical Systems - Theory and Applications / Lodz, 523-532.

[15] Orecny, M. (2015). Semi-active suspension of a horizontal platform with magnetorheological dampers and dynamic absorbers (in Slovak). Doctoral Thesis, Technical University of Košice, Faculty of Mechanical Engineering.

[16] Zong, L.-H., Gong, X. L., Guo, C.-Y., \& Xuan, S. H. (2012). Inverse neuro-fuzzy MR damper model and its application in vibration control of vehicle suspension system. Vehicle System Dynamics, 50(7), 1025-1041. https://doi.org/10.1080/00423114.2011.645489

[17] Palka, P. \& Maślanka, M. (2013). Inverse LuGre model for a small-scale MR damper. Proceedings of the $14^{\text {th }}$ International Carpathian Control Conference / Krakow Rytro, 284-287. https://www.researchgate.net/publication/260970597_Inverse_LuGre_model_for_a_small-scale MR_damper

[18](2015). Global Optimization ToolboxUser's Guide. The MathWorks, Inc., Natick.

\section{Contact information}

Stefan SEGLA, PhD, Full Professor

Technical University of Košice,

Faculty of Mechanical Engineering,

Letná 9, 04200 Košice, Slovakia

E-mail: stefan.segla@tuke.sk

Milos MUSIL, PhD, Full Professor

Slovak University of Technology in Bratislava,

Faculty of Mechanical Engineering,

Nám. Slobody 17, 81231 Bratislava, Slovakia

E-mail: milos.musil@sjf.stuba.sk 